NASA Technical Memorandum 89854

AIAA-87-0993

\title{
2000-Hour Cyclic Endurance Test of a Laboratory Model Multipropellant Resistojet
}



W. Earl Morren and James S. Sovey

Lewis Research Center

Cleveland, Ohio

Prepared for the

19th International Electric Propulsion Conference cosponsored by the AIAA, DGLR, and JSASS

Colorado Springs, Colorado, May 11-13, 1987. 


\author{
2000-HOUR CYCLIC ENDURANCE TEST OF A LABORATORY \\ MODEL MULTIPROPELLANT RESISTOJET \\ W. Earl Morren and James S. Sovey \\ National Aeronautics and Space Administration \\ Lewis Research Center \\ Cleveland, Ohio 44135
}

\title{
SUMMARY
}

This paper presents some results of an effort to demonstrate the technological readiness of a long-life multipropellant resistojet for space Station auxiliary propulsion. A laboratory model resistojet made from grain-stabllized platinum served as a test bed to evaluate the design characteristics, fabrication methods, and operating strategies for an engineering model multipropellant resistojet developed under contract by the Rocketdyne Division of Rockwe 11 International and Technion Incorporated. The laboratory model thruster was subjected to a 2000-hr, 2400-thermal-cycle endurance test using carbon dioxide propellant. Maximum thruster temperatures were approximately $1400{ }^{\circ} \mathrm{C}$. The post-test analyses of the laboratory model thruster included an investigation of component microstructures. Significant observations from the laboratory model thruster are discussed as they relate to the design of the engineering model thruster.

\section{INTRODUCTION}

This paper presents the results of a $2000-\mathrm{hr}, 2400$-thermal-cycle endurance test of a laboratory model resistojet made from grain-stabilized platinum using carbon dioxide propellant. Multipropellant resistojets have been baselined as the low-thrust option for the Space Station propulsion system. The resistojet can provide low levels of thrust for drag make-up while disposing of a variety of fluids expected to be present in excess quantities on board Space Station. The use of such fluids as propellant will result in significant reductions in Space Transportation System (STS) costs which would be associated with launching of the necessary propellants as well as the removal of waste fluids from Space Station. Recent studies have explored these and other potential benefits of a propulsion system incorporating low-thrust resistojets (refs. 1 and 2).

The NASA Lewis Research Center is actively involved in propulsion component technology in support of the Space Station Advanced Development Program (refs. 3 and 4 ). A substantial part of these efforts has focused on material evaluation, fabrication methods, performance, plume evaluations, and life assessments of resistojet technology for Space Station application. The technology goals emphasize thruster $11 \mathrm{fe}$, reliability, and multipropellant capability rather than optimum performance. The design life goal is a minimum of $10000 \mathrm{hr}$ for thrusters operating on hydrogen, helium, methane, water (steam), nitrogen, air, argon, and carbon dioxide at specific impulse and thrust levels of 100 to $500 \mathrm{sec}$ and 130 to $450 \mathrm{mN}$, respectively.

The main objectives of this program were to evaluate thruster material/ propellant compatibility and fabrication methods as well as provide preliminary lifetime data for a resistojet. A simple laboratory model resistojet was 
fabricated from grain-stabilized platinum and characterized on a variety of propellants at heater temperatures up to $1400{ }^{\circ} \mathrm{C}$ (ref. 5). A duplicate of this thruster was subjected to an endurance test operating in a thermallycyclic mode using carbon dioxide propellant. This thruster served as a test bed to provide insight into the design of a long-life engineering model resistojet for Space Station application (ref. 6). The engineering model resistojet is the second generation thruster developed under the Space Station Advanced Development Program. Valuable information regarding long-term endurance testing of space propulsion devices in ground test facilities was also gained.

\section{APPARATUS AND PROCEDURE}

\section{Laboratory Model Resistojet Description}

The material used for construction of the laboratory model resistojet was grain-stabilized platinum because it exhibits long-term, high-temperature compatibility with a wide variety of oxydizing and reducing fluids (refs. 7 and 8). The platinum used was manufactured by Johnson-Matthey, and employed a small quantity (less than 1 percent) of zirconium oxide dispersant as a grain stabilizer. The grain stabilization is desired to minimize grain growth which occurs when materials are held at high temperatures for extended periods of time. Excessive grain growth leads to distortion and weakening of components, which is of special concern for the pressure vessel/heat exchanger of a resistojet.

The laboratory model resistojet, shown in figure 1 , was a radiativelycoupled device employing a heating element located in an evacuated cavity within an annular heat exchanger body. The heat exchanger consisted of two concentric tubes sealed together to permit contained gas flow within the annular region between them. A spiral channel near the rear (inlet end) of the heat exchanger directed the flow of the cold incoming gas circumferentially to reduce heat loss from the rear of the thruster. The flow was then directed axially by 16 small channels in the forward (hottest) section of the heat exchanger, after which the gases were expanded through the nozzle. The heating element was made from a colled tube comprised of 22 turns over a length of $5.8 \mathrm{~cm}$. The platinum thruster components were joined by electron beam welds. Basic dimensions of the laboratory model resistojet are summarized in table I. To prevent heater coil sag due to operation in standard gravitational acceleration, a support structure, made from alumina, was incorporated in the heater element. This support structure (fig. $1(c)$ ) consisted of a $6.4 \mathrm{~mm}$ diameter by $6.0 \mathrm{~cm}$ long rod located in the center of the platinum coil and one length of $1.2 \mathrm{~cm}$ od by $1.0 \mathrm{~cm}$ id alumina tubing surrounding each end of the heater coil. While interactions between alumina and grain-stabilized platinum at high temperatures have been observed to cause degradation of the platinum structure (ref. 9), preliminary tests suggested that applying a thin coating (nominally $2000 \mathrm{~A}$ ) of platinum to the alumina surface retards this interaction. Further protection of the platinum components was provided by a layer of $0.03 \mathrm{~mm}$ platinum foil between the outer surface of the alumina tubes and the inner surface of the heat exchanger. To minimize radiative heat losses from the outer surface of the heat exchanger, the thruster was wrapped with radiation shielding consisting of two layers of $0.03 \mathrm{~mm}$ platinum foil followed by 
13 layers of $0.13 \mathrm{~mm}$ stainless steel foil. The layers of shielding were separated by small diameter wires.

\section{Pre-Test Analysis}

The purpose of the pre-test analysis was to thoroughly describe the condition of the test thruster prior to initiation of the endurance test. This characterization consisted of an electrical calibration of the heater element, a brief performance test, and documentation of critical thruster dimensions.

The electrical calibration of the heater element gave the relationship between the heater temperature and elecrical resistance. This allowed the resistance to be used as an indication of heater integrity during the course of the endurance test. During this calibration the heater temperature was measured with a two-color optical pyrometer, and resistances were measured for temperatures from 900 to $1400{ }^{\circ} \mathrm{C}$.

The purpose of the pre-test performance test was not to probe the limits of the capabilities of the test article, but to provide a benchmark against which any changes in thruster behavior could be gauged and to aid in the selection of operating conditions during the endurance test. The pre-test performance test was conducted by measuring cold-flow performance at two thrust levels and warm-flow performance at three thrust levels with heater temperatures of approximately $1400{ }^{\circ} \mathrm{C}$. The apparatus used for obtaining the performance data has been described in reference 5 .

\section{Endurance Test}

The endurance test was carried out in a test chamber measuring $0.6 \mathrm{~m}$ in diameter by $1.0 \mathrm{~m}$ long, equipped with a rotary piston vacuum pump. The thruster was operated for a total of $24001-\mathrm{hr}$ thermal cycles with a heater duty cycle of 83 percent and propellant mass flow rate held approximately constant at $0.12 \mathrm{~g} / \mathrm{s}$. The propellant used was high-purity carbon dioxide, and was chosen because it could be stored in liquid form, was inert (important for facility safety considerations), and was a likely candidate for use as a propellant on board space Station. Heater voltage and current, propellant mass flow rate, thruster inlet pressure, and temperatures at three locations on the outer layer of the radiation shielding were all monitored continuously during the test. Figure 2 shows a schematic representation of the endurance test apparatus. The heater was operated at $29.0 \mathrm{~A}$ in a current-limited mode. This current level was chosen to produce an equilibrium heater temperature of $1400{ }^{\circ} \mathrm{C}$ at the beginning of the test. The choice of heater temperature was based on the expectation that the flight model resistojet would also be operated at up to $1400{ }^{\circ} \mathrm{C}$, a temperature at which the glass fabrication industry has extensive experience with operation of grain-stabilized platinum heaters. Figure 3 shows the laboratory model resistojet mounted on the vacuum facility flange prior to initiation of the endurance test. Test facility pressure during the test remained approximately constant at $40 \mathrm{~Pa}(0.3$ tor $)$. 
The endurance test was voluntarily terminated at the completion of 2400 thermal cycles and $2000 \mathrm{hr}$ under power. The resistojet was removed from the test chamber and subjected to a series of post-test inspections intended to thoroughly document its condition. The critical thruster dimensions were recorded, cold and hot performance was documented, and the electrical characteristics of the heater element were evaluated. The post-test analyses also included a complete sectioning of the heater and heat exchanger to allow examination of the platinum microstructures at various places throughout the thruster. This provided information regarding the effects of extended hightemperature operation and electron beam weld joining on the grain-stabilization properties of the platinum.

\section{RESULTS AND DISCUSSION}

Heater Characterization

Figure 4 shows the results of the electrical characterizations performed before and after the endurance test. Figure 5 shows the variation in heater voltage during the course of the test. Both of these figures indicate a drop in heater resistance during the test. Upon disassembly of the thruster it was learned that 5 of the 22 turns of the heater coil were shorted (fig. 6(a)). This shorting occurred when coils moved axially along the alumina support rod during the cyclic expansion and contraction of the heater. Nonuniformities in this motion caused bunching at various locations along the heater length and resulted in the observed shorting.

The heater and heat exchanger design employed in the engineering model resistojet was chosen to eliminate heater shorting due to movement as observed in the laboratory model thruster. The engineering model design is based on a sheathed heater, which consists of a rugged platinum/rhodium heater wire surrounded by a layer of magnesium oxide insulation, all of which is contained in a grain-stabilized platinum sheath. This assembiy is processed by swaging the outer sheath, compacting the magnesia between the sheath and the center conductor, and insuring proper centering of the conductor within the sheath. The heater is wound around a central heat exchanger which incorporates a series of semicircular grooves in the forward section designed to hold the heater in place while providing a large surface area for heat conduction. Figure 6(b) shows details of the sheathed heater used in the engineering model resistojet.

\section{Performance Characterizations}

The purposes of the pre-test performance characterization were to provide a basis for selection of the thruster operating conditions during the life test as well as to allow for exposure of any gross degradation of thruster condition, such as gas leaks. It was desirable that the test thruster operate at a mass flow rate and maximum temperature of $\sim 0.12 \mathrm{~g} / \mathrm{s}$ and $1400{ }^{\circ} \mathrm{C}$, respectively, since these were the nominal operating conditions anticipated for the engineering model resistojet. The data gathered during the pre-test characterization indicated that a current level of $29.0 \mathrm{~A}$ at the specified mass flow rate would produce the desired conditions. However, some difficulty in keeping 
the heater coil centered in the heat exchanger was experienced at the initiation of the endurance test. Therefore two sections of platinum-coated alumina tubing were installed around the heater coil to keep it centered. The addition of these tubes caused a change in the thermal environment around the last three turns on each end of the heater coil, resulting in a reduction in temperature in these regions for a given heater current. This caused the average resistance of the heater to decrease for a given operating condition. The temperature in the center of the heater coil is believed to have remained at $1400{ }^{\circ} \mathrm{C}$ for a current of $29.0 \mathrm{~A}$ although the average temperature indicated by the resistance measurement at the initiation of the test was about $1300{ }^{\circ} \mathrm{C}$. Comparison of the beginning-of-test performance data to the end-of-test performance data (table II) indicated a significant reduction in warm-gas performance during the test. The heater shorting caused by axial movement of the colls was the apparent cause of this reduced performance, since the lower heater resistance reduced the maximum power which could be dissipated. No degradation in cold-gas performance was observed, so no gas leaks were indicated.

\section{Structural Integrity}

The effects of prolonged high-temperature, cyclic operation in a ground test facility, and joining of thruster components using electron-beam welds on the grain stabilization of platinum were of major interest, since the engineering model thruster is fabricated from this material. While some data on the stress-rupture and creep properties of grain-stabilized platinum are available in the literature (ref. 10), no data for test times in excess of $1000 \mathrm{hr}$ were available.

To evaluate the post-test condition of the platinum microstructure, several cross-sections of the laboratory model thruster were polished and photographed at magnifications up to $200 x$. Figure 7 shows the locations on the thruster where photomicrographs were obtained.

Figure 8 shows an axial section of the nozzle throat. The grains in the immediate vicinity of the nozzle throat are significantly smaller than the grains in the surrounding material. This observation was not expected, since the throat was one of the hottest regions in the heat exchanger and should have exhibited increased grain growth over cooler areas. However, the machining processes employed during fabrication of this part included drilling of the nozzle hole as well as additional working to produce a smooth transition from the throat into the nozzle cone. This level of cold working could account for the relatively small grains in this region. Comparison of the post-test condition of this part to the pre-test condition of an identically-processed part would be desirable, but no additional unused parts were available for sectioning.

The joining of grain-stabilized components using welds has been observed to destroy the oxide dispersion, causing enhanced grain growth within the weid region. Figure 9 shows four sections of electron-beam (EB) welds within the thruster. Figures $9(a)$ and (b) show the nature of the grain-stabilized platinum tube-to-flange joints (section numbers 1 and 2 in fig. 7). The tube, or shell, exhibits a plate-like grain structure with a low aspect ratio (width/ length), whereas the character of the weld grains more closely resembles that of pure platinum as shown in reference 9. As expected, the grain-stabilized 
characteristics no longer exist within the weld regions. Figures $9(c)$ and (d) show the grain structures at two points within the tube-to-nozzle EB weld (section numbers 3 and 4 in $\mathrm{fig} .7$ ). The broken white lines indicate the interface between the components prior to welding. Note that the weld shown in figure $9(\mathrm{c})$ did not fully penetrate the intended weld region, leaving a void through approximately one-third of the pressure vessel wall. Figure 9 (d) shows a similar result, but not to the same extent. This condition was present through $\sim 50$ percent of the tube-to-nozzle weld circumference, indicating the need for further experimentation to determine the optimum EB weld energy density for such joints. Table III shows the energy densities (total weld energy/ weld length) used to perform each of the welds shown in figure 9 . An interesting feature of the welds in figure $9(c)$ and (d) is that the grains in the weld regions are no larger, in general, than those in the regions surrounding the weld. In fact, some of the grains within the welds appear to be smaller than those in the surrounding material. It is possible that these relatively small grains were caused by migration of the stablization dopant, zirconia, to the grain boundaries where it was still able to retard growth of the grains. This situation may still tend to weaken the weld region and the load-bearing joints in the engineering model resistojet, therefore, employ diffusion bonding over relatively large surface areas with back-Up EB welds to ensure gas-tight integrity.

Figures $10(a)$ and (b) show sections of the inner heat exchanger shell in the gas inlet region and near the nozzle, respectively. It is apparent that the grains in the inlet (cooler) region are smaller than those in the highertemperature nozzle region. Typical grain dimensions in figure 10(b) are about $0.8 \mathrm{~mm}$, or 10 percent of the heat exchanger wall thickness. The temperature in this region was estimated to have operated at $600{ }^{\circ} \mathrm{C}$ during the majority of the endurance test, although this temperature was probably closer to $800{ }^{\circ} \mathrm{C}$ during the first 300 thermal cycles. These estimates are based on calculated values for the stagnation enthalpies of the propellant and an assumed temperature difference between the gas and heat exchanger. The gas stagnation enthalpy was obtained by first calculating the thrust power (based on measured values of thrust and mass flow rate), then dividing by an estimate of the square of the nozzle efficiency and the mass flow rate:

$$
h_{0}=\frac{T I_{s p} g_{e}}{2 \dot{m}\left(n_{n o z}\right)^{2}}
$$

The nozzle efficiency is defined as the ratio of measured to ideal specific impulse and $\mathrm{ge}_{\mathrm{e}}$ is standard gravitational acceleration. The resulting enthalpy value was then used with standard gas property tables (ref. 11) to determine the gas stagnation temperature. The value of the nozzle efficiency was assumed to be 0.92 based on the measured value of the cold gas efficiency of the test thruster. The resulting calculated gas temperature is lower than the exact value because the nozzle efficiency used was higher than would actually be experienced during warm gas operation due to increased viscous losses at reduced Reynolds numbers.

Figures $11(a)$ and (b) show sections of one of the heater tube coils. During the test the heater tube operated at temperatures estimated to be 900 to $1400{ }^{\circ} \mathrm{C}$, the lower temperatures being associated with the areas where colls 
had shorted together. The heater was expected to show the greatest sensitivity to time and temperature effects on the grain structure. Figure 11(a) shows a plane normal to the tubing axis, while figure 11(b) views a plane parallel to the tubing axis. Note that the grains still exhibit an elongated shape with typical grain lengths several times the typical grain width. Figure 11(a) shows that many grains span the entire thickness of the tubing wall (about $0.25 \mathrm{~mm}$ ). Since the engineering model thruster pressure vessel walls are $2.5 \mathrm{~mm}$ thick, grains of this size would be $\sim 10$ percent of this wall thickness, a condition which was present in the pressure vessel of the laboratory model thruster and caused no apparent problems during $2000 \mathrm{hr}$ of operation.

Grain dimensions are known to approach a maximum value asymptotically with time at a given temperature (ref. 12). Reference 8 data shows that significant growth can occur during annealing at $1000^{\circ} \mathrm{C}$, although the extent of further grain growth cannot be ascertained due to limitations on grain size imposed by the sample dimensions. Likewise, the point on the growth curve represented by the microstructures shown in figure 11 cannot be identified (i.e., these grain dimensions could have been limited by the tubing dimension or by operating temperature). Thus, the grains in the pressure vessel walls of the engineering model thruster could grow larger than those observed in the laboratory model heater since the engineering model section provides more room to grow. There are then two questions which must be answered: (1) how large would the grains in a grain-stabilized platinum sample of large cross-section be after several thousand hours at temperatures of importance to the design of the engineering model thruster?, and (2) how large can the grains within the pressure vessel walls of the engineering model thruster be before the structural integrity is unacceptably compromised? An investigation to determine the relationships between time at temperature and grain size in grainstabilized platinum samples representative of the engineering model pressure vessel would be valuable.

Figure 12 shows a section of the heater termination disc with the platinum foil shims (used to affect a tight fit between the heater termination and the inside of the heat exchanger to enhance electrical conductivity). Several of the grains have grown across the boundaries between the $0.02 \mathrm{~mm}$ shim layers, indicating the ease with which platinum diffusion bonds at temperatures near $1000^{\circ} \mathrm{C}$. This observation is of importance because diffusion bonds form the load-bearing joints in the engineering model thruster pressure vessel.

The environment in the test chamber during the endurance test caused no apparent contamination of the grain-stabilized platinum thruster material. This observation indicates that future endurance tests on platinum thrusters can be conducted in similar test environments without fear of facility effects introducing error into the test results.

\section{Engineering Model Resistojet Design.}

The purpose of this endurance test was to serve as a test bed for material compatibility, hardware fabrication processes, operating conditions, and strategies for ground testing multipropellant resistojets with long life characteristics. The information gained from this test has yielded valuable insight into the design of the engineering model resistojet which will serve as a preprototype space station thruster. The engineering model resistojet 
incorporates significant design improvements over the laboratory model thruster which will give it reliable long-life characteristics (ref. 6). Figure 13 shows a photograph of the engineering model resistojet as well as a crosssectional drawing showing the internal layout. Among the most significant differences between the laboratory model and engineering model resistojets are:

(1) The colled tube heater is replaced by a colled sheathed heater. This eliminates the potential for shorting of the heater by surrounding the currentcarrying resistance element with a layer of compressed magnesia insulation, which is covered with a metal sheath. The sheathed heater is wound around a rugged central heat exchanger and is secured in position by a series of semicircular grooves machined into the outer surface of the forward half of the heat exchanger. This feature eliminates the possibility of movement of the heater, which would result in changes in the thermal characteristics of the thruster, and provides a large contact area between the heater and heat exchanger. The temperature difference between the heater and heat exchanger in this design is inherently low, and preliminary thermal tests on the first engineering model indicate that its temperature drop is less than $200{ }^{\circ} \mathrm{C}$ for a nominal heater temperature of $1200{ }^{\circ} \mathrm{C}$.

(2) Large-surface-area diffusion bonds replace the stress-bearing EB welds used in the laboratory model thruster. The diffusion bonds are backed by $E B$ welds located in relatively cool regions of the engineering model thruster to ensure gas-tight integrity. This joining technique eliminates potential failures due to adverse effects on the grain stabilization of the platinum by the EB welding process.

(3) A thick-walled pressure vessel/heat exchanger replaces the thin-walled pressure vessel employed by the laboratory model thruster. This change improves the stress-rupture characteristics of the engineering model resistojet. However, the question of grain growth within the walls of the engineering model heat exchanger persists, since the thruster heat exchanger is planned to operate at a maximum temperature of 1200 to $1400{ }^{\circ} \mathrm{C}$.

\section{CONCLUDING REMARKS}

Resistojet thrusters capable of operating for extended periods of time on a variety of propellant fluids have been baselined as the low-thrust option for Space Station propulsion. Their benefits include simplicity, low cost, and the ability to provide drag make-up while disposing of fluids which would otherwise have to be removed from Space Station via Shuttle. These waste fluids can be vented either propulsively or nonpropulsively, ensuring that fluids such as steam and carbon dioxide will not condense during expansion to vacuum.

To provide insight into the problems of long-life operation of a multipropellant resistojet, a laboratory model thruster fabricated from grainstabilized platinum was subjected to a 2000-hr, 2400-thermal-cycle endurance test using carbon dioxide propellant.

The propellant inlet pressure ranged from 0.10 to $0.17 \mathrm{MPa}$ during the test, exerting a maximum hoop stress of $3.2 \mathrm{MPa}$ on the outer wall of the heat exchanger, which is estimated to have operated at a maximum temperature of 
$600{ }^{\circ} \mathrm{C}$ during most of the test. No degradation in the integrity of the heat exchanger/pressure vessel was observed. Evidence of mechanical distortion occurred in the heater element, which exhibited significant motion of the colls along the alumina heater support rod, causing shorting and reduction in power level.

The microstructures of the grain-stablilized platinum pressure vessel components generally exhibited an elongated, cylindrical shape except at the electron beam-welded joints and in the vicinity of the nozzle throat. The grains in these regions appeared more nearly spherical. The weld grains shapes were caused by the melting and recrystalization experienced during joining, while the grains near the nozzle throat are believed to have been broken down during fabrication of this part. The microstructures of the heater coil tubing, which operated at temperatures of 900 to $1400{ }^{\circ} \mathrm{C}$ during the test, showed grain dimensions which were generally of the same order as the walls of the heater tubing. It is possible that the grain size was limited by the tubing dimension rather that the operating conditions or duration of the endurance test. The grain dimensions in the hottest section of the laboratory model heat exchanger were on the order of $0.05 \mathrm{~mm}$, or $\sim 10$ percent of the pressure vessel wall thickness. These sections are estimated to have operated at $600{ }^{\circ} \mathrm{C}$ for most of the endurance test duration. Furthermore, the grains in the heat exchanger walls are believed to have reached their maximum size, since the rate of grain growth generally decreases with increasing time at temperature.

The results obtained from the endurance test performed on the laboratory model resistojet yielded valuable insight into the design of an engineering model resistojet. The design of the engineering model thruster incorporates significant improvements over the laboratory model. Specifically, the problem of heater shorting due to distortion has been eliminated by using a rugged colled sheathed heater wrapped around a thick-walled heat exchanger incorporating a series of semicircular retaining grooves in the forward section. The use of stress-bearing diffusion bonds backed by electron beam welds in the engineering model resistojet provides an excellent gas-tight load bearing joint. The use of a thicker wall section and a smaller inside diameter in the engineering model pressure vessel than in the laboratory model resulted in an 87 percent reduction in hoop stress and an 80 percent reduction in the ratio of grain dimension to wall thickness. If the engineering model is operated with a maximum pressure vessel temperature of $600^{\circ} \mathrm{C}$, a significant margin of safety will exist with respect to stress level and grain growth. Thus a safe operating temperature limit has been established for the engineering model thruster.

At the outset of this program the maximum operating temperature for the engineering model resistojet was chosen to be $1400{ }^{\circ} \mathrm{C}$. This 1 imit was chosen because of extensive glass fabrication industry experience in the operation of grain-stabilized platinum at $1400^{\circ} \mathrm{C}$ for periods in excess of $10^{4} \mathrm{hr}$. However, microstructures of the laboratory model heater tubing, which operated at 900 to $1400{ }^{\circ} \mathrm{C}$, suggested that excessive grain growth might become a problem if the engineering model thruster were operated at $1400{ }^{\circ} \mathrm{C}$. An evaluation of the dependence of grain growth upon time and temperature would yield important insight into the maximum safe operating temperature for the engineering model resistojet. 


\section{REFERENCES}

1. Donovan, R.M., Sovey, J.S., and Hannum, N.B., "Space Station Propulsion Analysis Study," AIAA Paper No. 84-1326, June 1984.

2. Garrison, P.W., and Klemetson, R.W., "Space Station Propulsion System Trade Study," AIAA Paper No. 83-1220, June 1983.

3. Jones, R.E., "Space Station Propulsion: The Advanced Development Program at Lewis," AIAA Paper No. 85-1154, July 1985.

4. Jones, R.E., "Highand Low-Thrust Propulsion Systems for Space Station," AIAA Paper No. 87-0398, January 1987.

5. Morren, W.E., Whalen, M.V., and Sovey, J.S., "Performance and Endurance Tests of a Multipropellant Resistojet for Space Station Application," AIAA Paper No. 86-1435, June 1985.

6. Pugmire, T.K., Cann, G.L., Heckert, B., and Sovey, J.S., "A 10,000-HourLife Multipropellant Engine for Space Station Application, " AIAA Paper No. 86-1403, June 1986.

7. Whalen, M.V., Grisnik, S.P., and Sovey, J.S., "Compatibility Experiments of Facilities, Materials, and Propellants for Electrothermal Thrusters," NASA TM-86956, 1985.

8. Whalen, M.V., and Grisnik, S.P., "Compatibllity of Grain-Stabilized Platinum with Candidate Propellants for Resistojets," AIAA Paper No. 85-2014, Sept. 1985.

9. Darling, A.S., Selman, G.L., and Rushforth, R., "Platinum and the Refractory 0xides," Platinum Metals Review, Vol. 15, No. 1, Jan. 1971, pp. 13-18.

10. Selman, G.L., Day, J.G., and Bourne, A.A., "Dispersion Strengthened Platinum: Properties and Characteristics of a New High-Temperature Material," Platinum Metals Review, Vol. 18, No. 2, Apr. 1974, pp. 46-57.

11. McBride, B.J., Heime 1, S., Ehlers, J.G., and Grodon, S., "Thermodynamic Properties to $6000^{\circ} \mathrm{K}$ for 210 Substances Involving the First 18 Elements," NASA SP-3001, 1963.

12. Private Communication. Nathal, M.V., NASA Lewis Research Center, Cleveland, OH, Nov. 1986. 
TABLE I. - MULTIPROPELLANT RESISTOJET DESIGN CHARACTERISTICS

\section{Shell/nozzle}

Material ....... Grain-stabilized platinum

Nozzle throat diameter, $\mathrm{mm}$. . . . . . . 0.84

Nozzle area ratio............. 82

Nozzle half angle, deg ......... 20

Body length, cm ............ 13.0

Body diameter, cm . . . . . . . . . 1.92

Heat exchanger

Material ....... Grain-stabilized platinum

Number of channels ........... 16

Heater element

Material ....... Grain-stabilized platinum

Tubing od, $\mathrm{mm} . . . . . . . . . . .2 .03$

Tubing id, $\mathrm{mm} . . . . . . . . . . . . .1 .52$

Coil length, cm ............ . 5.82

Coil pitch ............... . . 0.10

Coil diameter, $\mathrm{cm}$............ 1.04

Maximum operating

temperature, ${ }^{\circ} \mathrm{C} . . . . . . . . . ~ 1400$

Design life, hr.............. 10000

TABLE II. - SUMMARY OF ENDURANCE TEST OPERATING CONOITIONS

\begin{tabular}{|l|c|c|}
\hline & $\begin{array}{c}\text { Beginning of } \\
\text { test }\end{array}$ & $\begin{array}{c}\text { End of } \\
\text { test }\end{array}$ \\
\hline $\begin{array}{l}\text { Measured parameters } \\
\text { Inlet pressure, MPa }\end{array}$ & 0.18 & 0.16 \\
Mass flow rate, $\mathrm{kg} / \mathrm{sec}$ & $1.23 \times 10^{4}$ & $1.24 \times 10^{4}$ \\
Voltage, V & 6.70 & 4.40 \\
Current, A & 29.0 & 29.0 \\
Calculated parameters & & \\
Thrust, MN & 147 & 125 \\
Specific impulse, s & 122 & 103 \\
Resistance, $\Omega$ & 0.231 & 0.152 \\
Power, $W$ & 194 & 128 \\
Heater temperature, ${ }^{\circ} \mathrm{C}$ & 1400 & 900 \\
Heat exchanger temperature & 800 & 600 \\
(estimated), ${ }^{\circ} \mathrm{C}$ & & \\
\hline
\end{tabular}


TABLE III. - ELECTRON BEAM WELD ENERGY DENSITIES

FOR LABORATORY MODEL RESISTOJET

\begin{tabular}{|l|c|c|}
\hline \multicolumn{1}{|c|}{$\begin{array}{c}\text { Joint } \\
\text { description }\end{array}$} & $\begin{array}{c}\text { Energy density, } \\
\mathrm{kJ} / \mathrm{cm}\end{array}$ & $\begin{array}{c}\text { Figure } 7 \\
\text { reference number }\end{array}$ \\
\hline $\begin{array}{l}\text { Nozzle/pressure vesse1 } \\
\text { Pressure vesse1/ } \\
\text { flange front }\end{array}$ & 0.95 & 3,4 \\
$\begin{array}{l}\text { Inner heat exchange tube/ } \\
\text { flange rear }\end{array}$ & 1.2 & 1 \\
$\begin{array}{l}\text { Flange front/flange rear } \\
\text { Heater tube/heater term. } \\
\text { disk }\end{array}$ & .92 & 2 \\
\hline
\end{tabular}






(A) HEAT EXCHANGER-NOZZLE CROSS-SECTION.

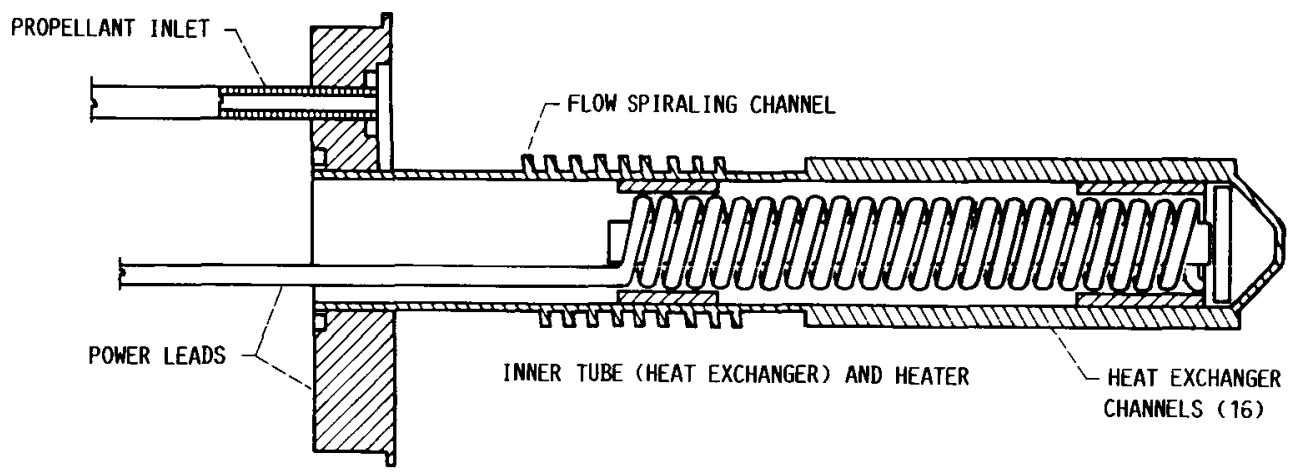

(B) HEATER - HEAT EXCHANGER.

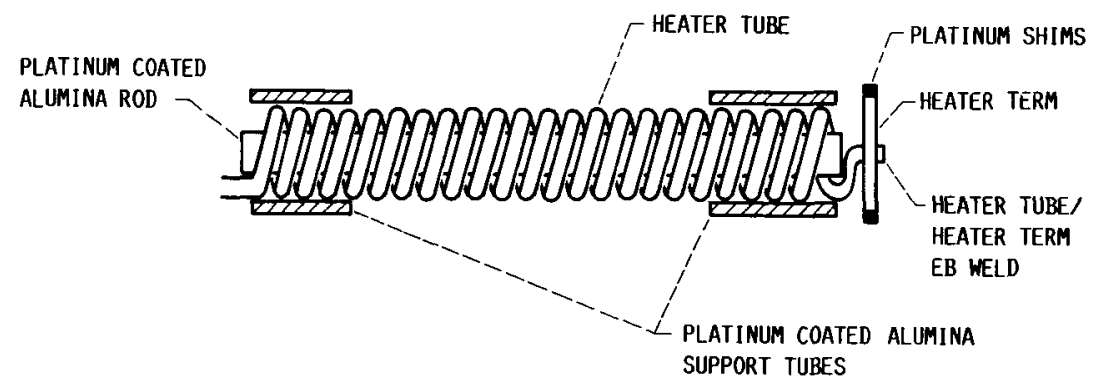

(C) HEATER AND SUPPORT STRUCTURE CROSS-SECTION.

FIGURE 1. - SCHEMATICS OF THE MULTIPROPELLANT RESISTOJET. 

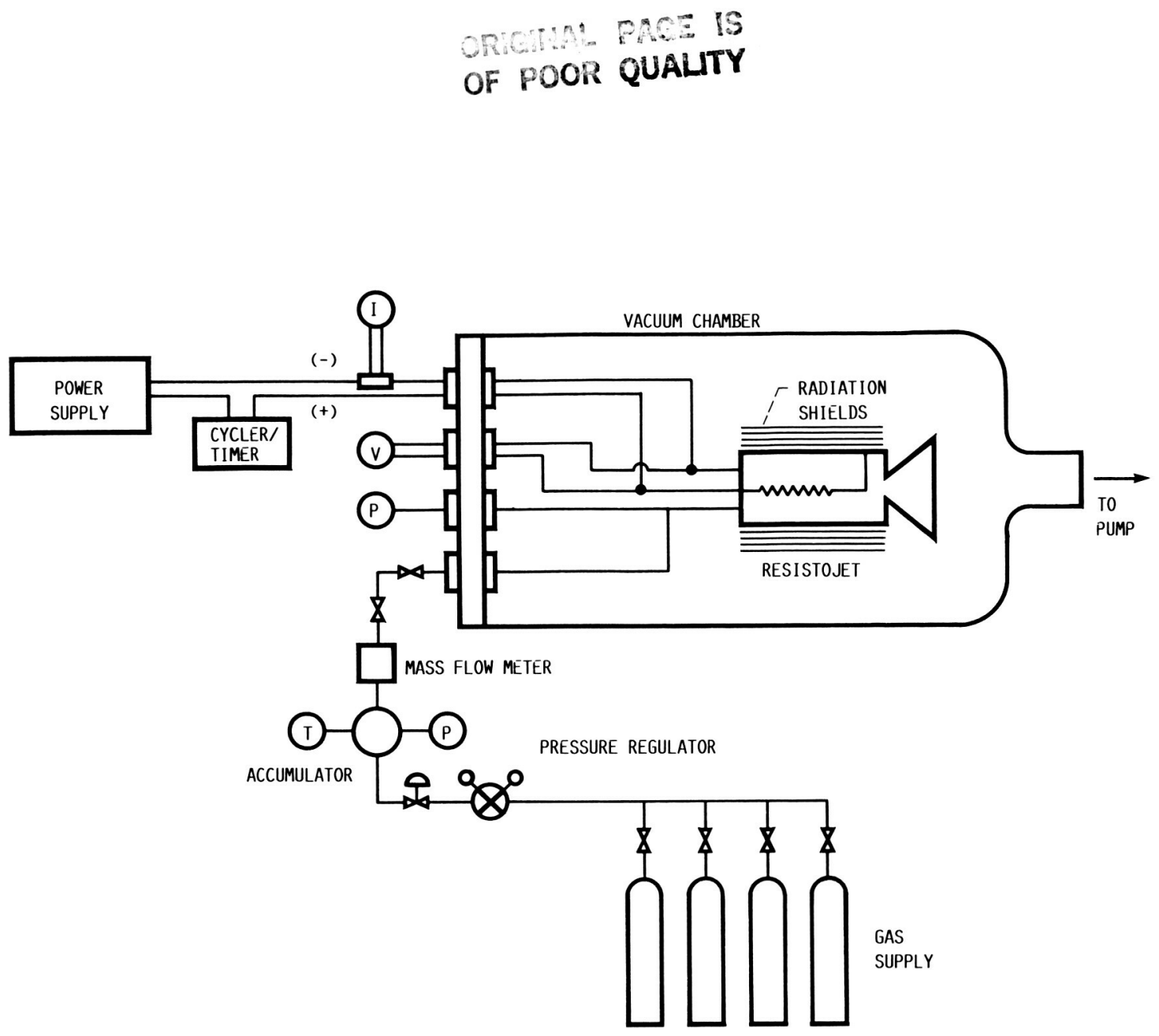

FIGURE 2. - SCHEMATIC DIAGRAM OF ENDURANCE TEST FACILITY.

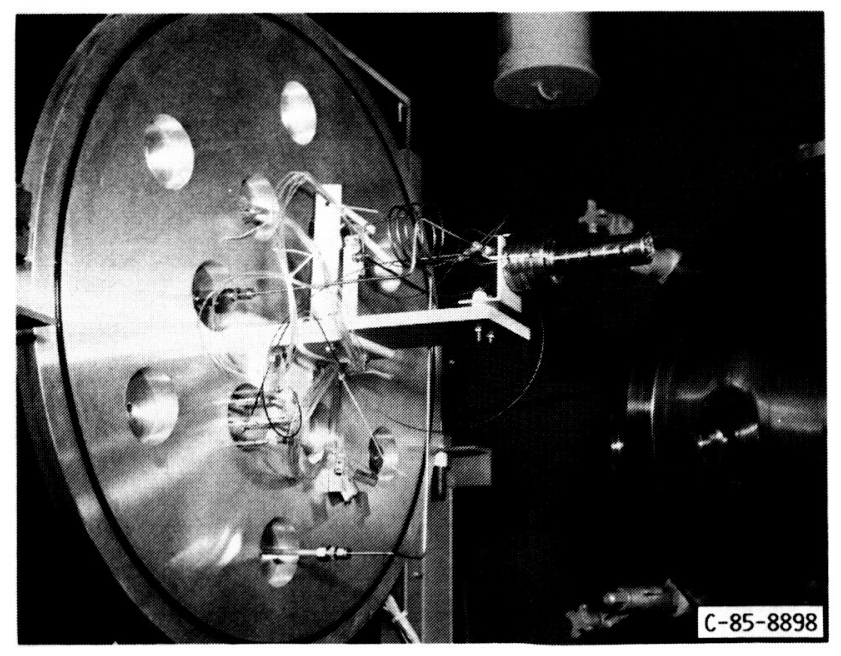

FIGURE 3. - MULTIPROPELLANT RESISTOJET INSTALLED IN ENDURANCE TEST FACILITY. 


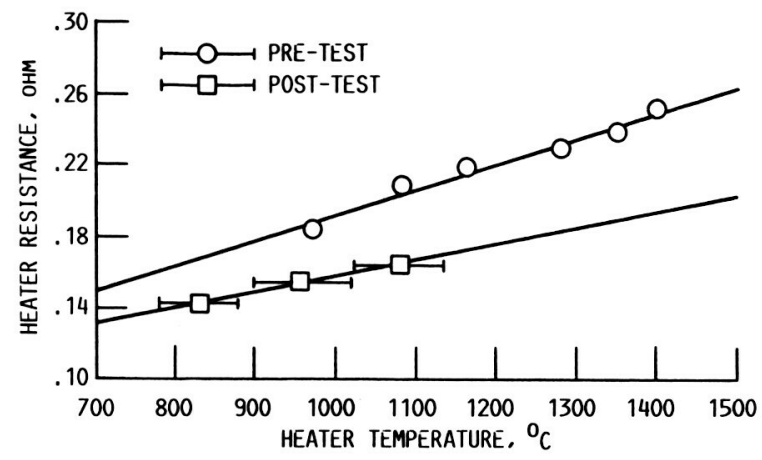

FIGURE 4. - MULTIPROPELLANT RESISTOJET HEATER ELECTRICAL CHARACTERIZATION. NOTE: ERROR BARS ON POST-TEST POINTS INDICATE OBSERVED TEMPERATURE RANGE.

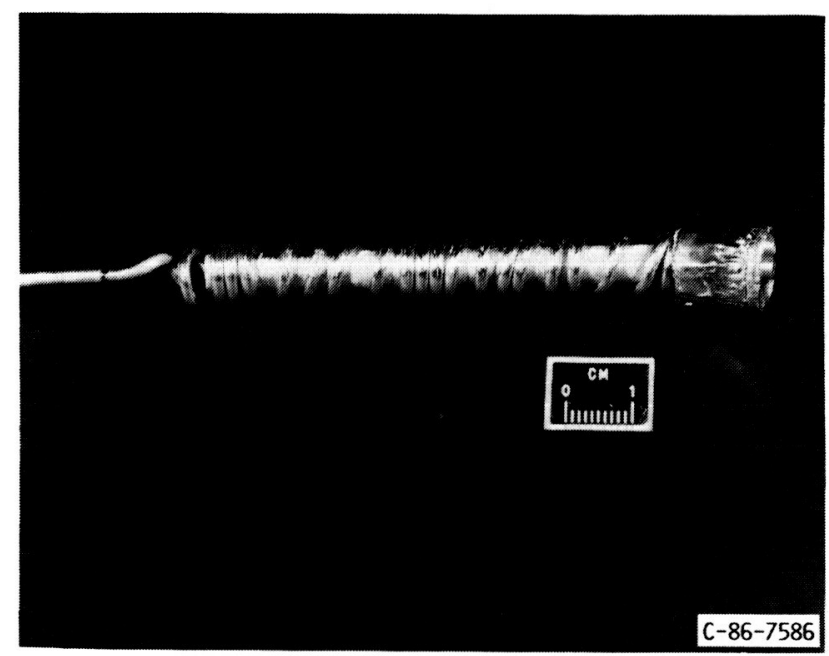

(A) HEATER FOR LABORATORY MODEL THRUSTER (POST TEST).

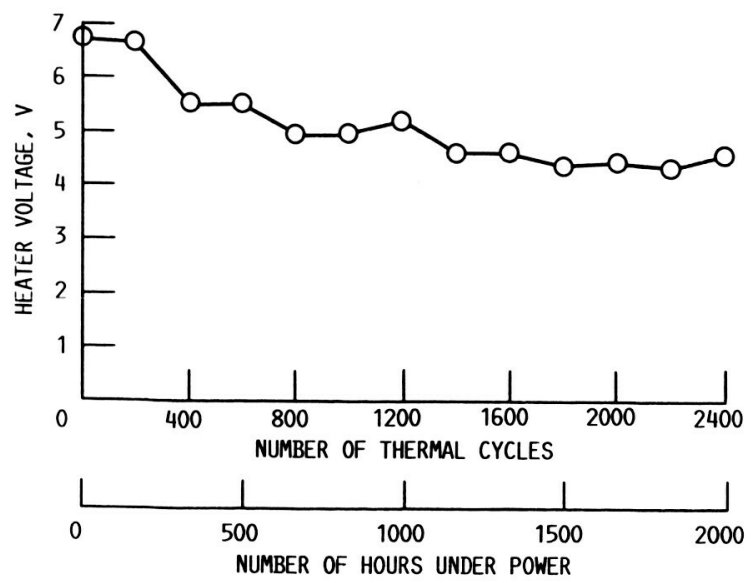

FIGURE 5. - HISTORY OF HEATER VOLTAGE DURING ENDURANCE TEST.

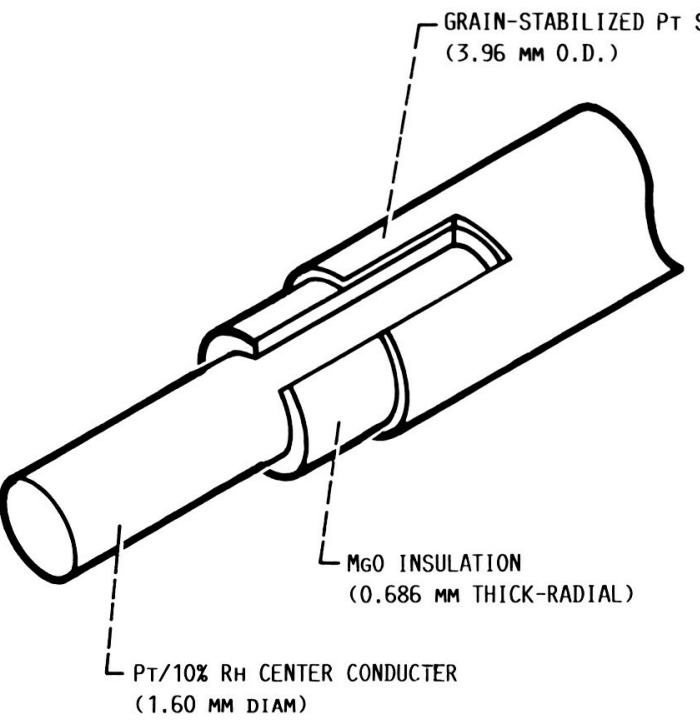

(B) HEATER FOR ENGINEERING MODEL THRUSTER.

FIGURE 6. - HEATERS FOR LABORATORY MODEL AND ENGINEERING MODEL THRUSTERS. 


\section{ORIGINAL PACE IS \\ OF POOR QUALITY}

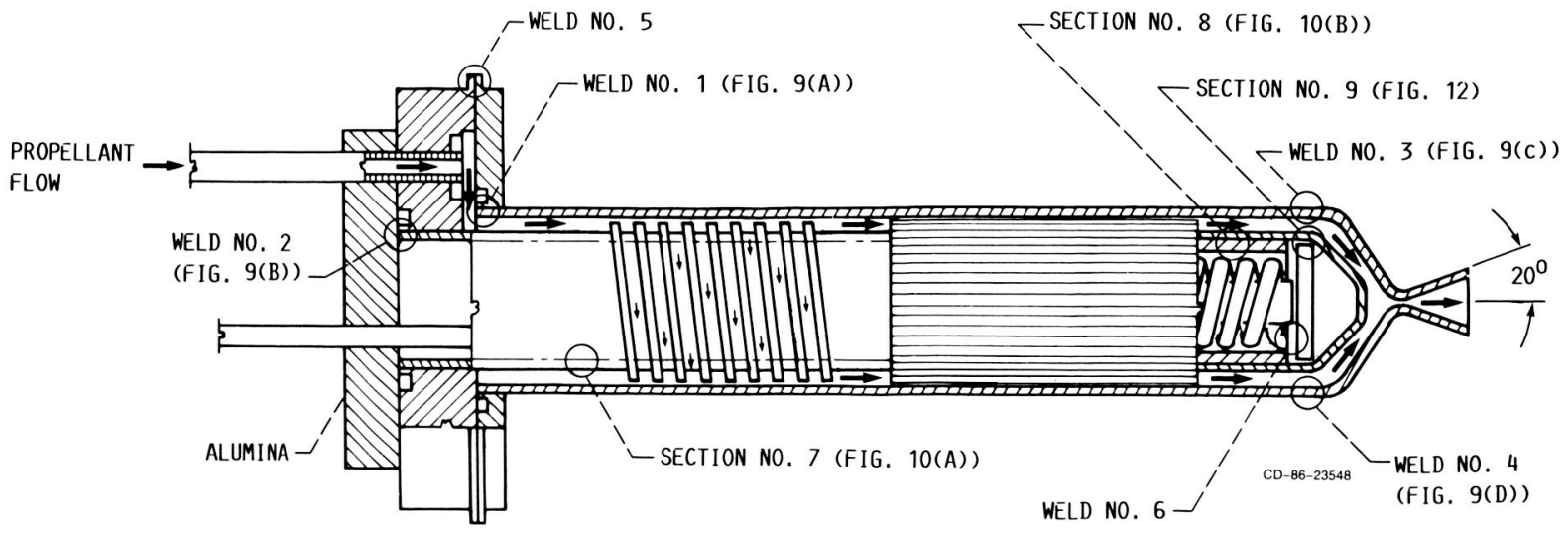

FIGURE 7.- LOCATIONS OF EB WELDS IN LABORATORY MODEL RESISTOJET REFERENCED IN TEXT, TABLE III.

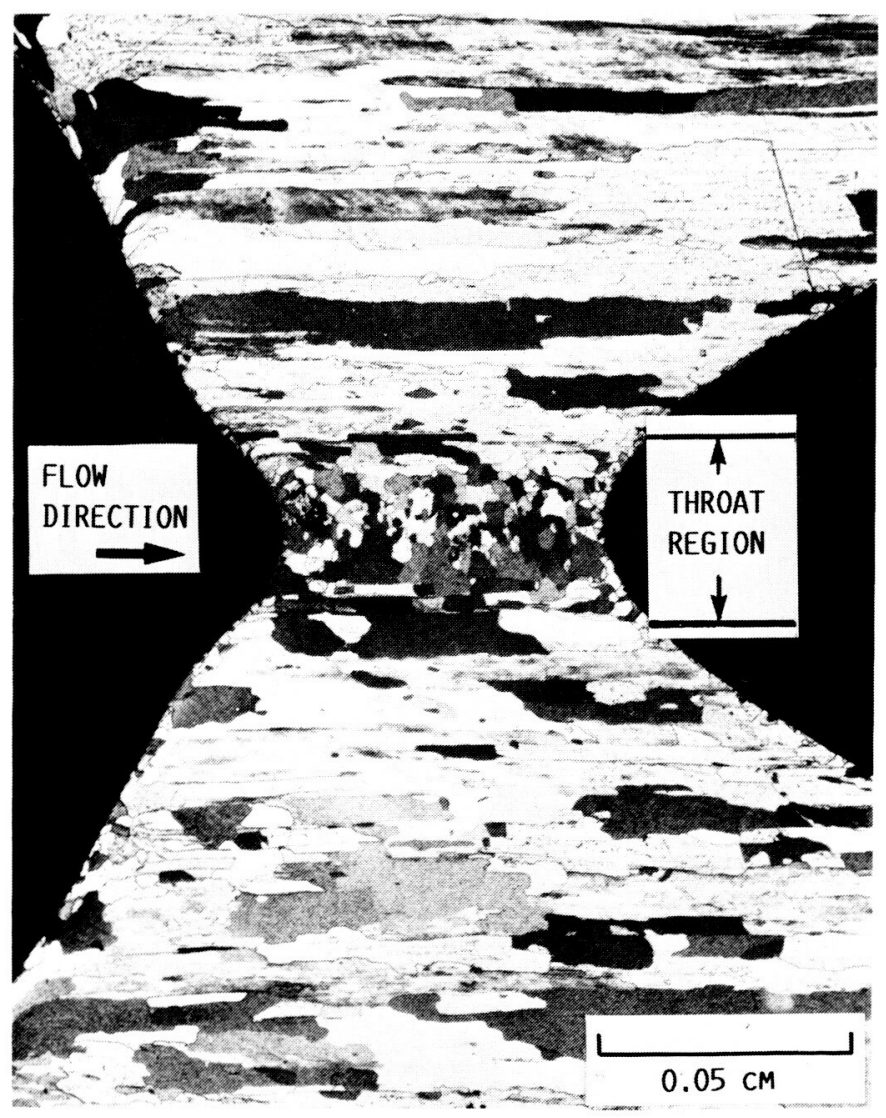

FIGURE 8. - GRAIN STRUCTURE AT NOZZLE THROAT. 


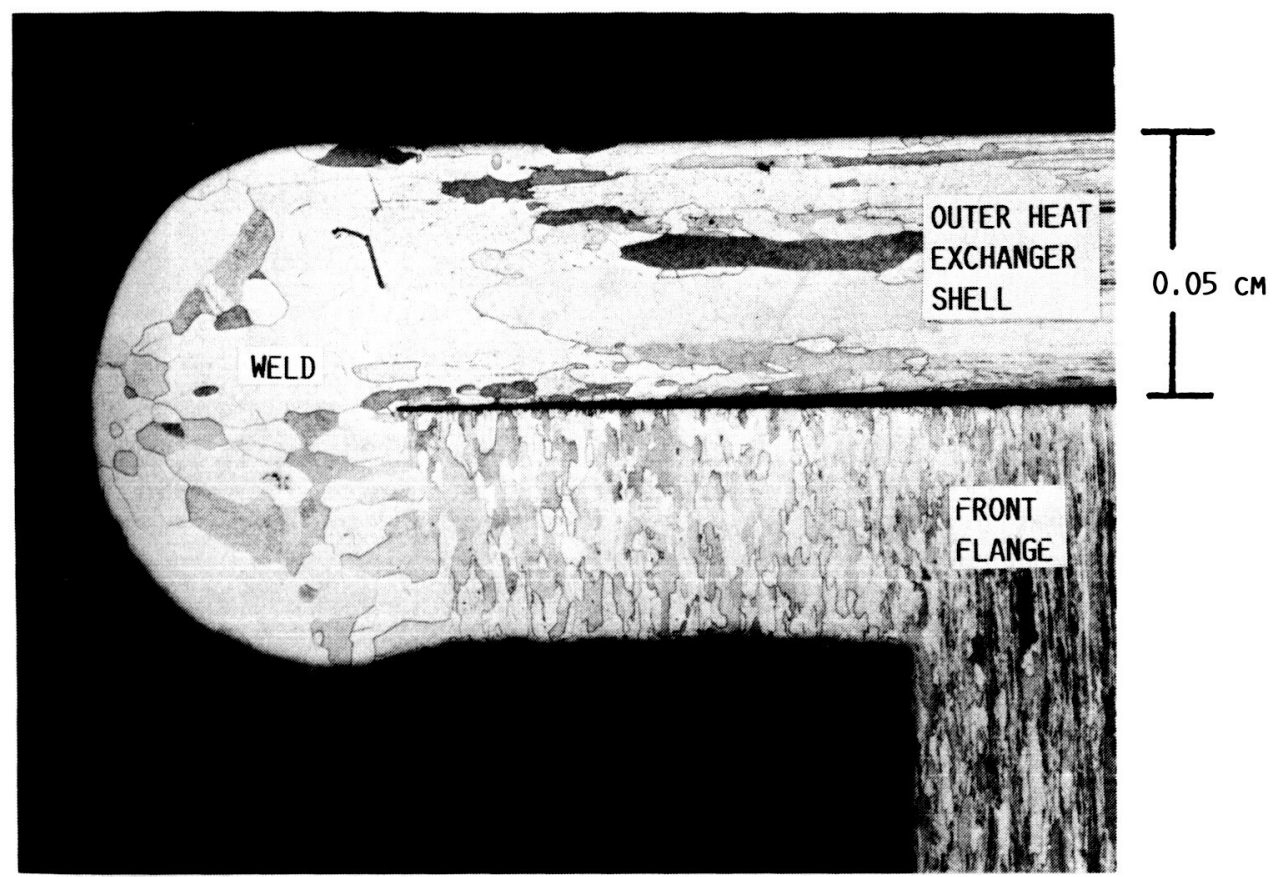

(A) FLANGE/PRESSURE VESSEL (EB WELD N0. 1, FIG. 7).

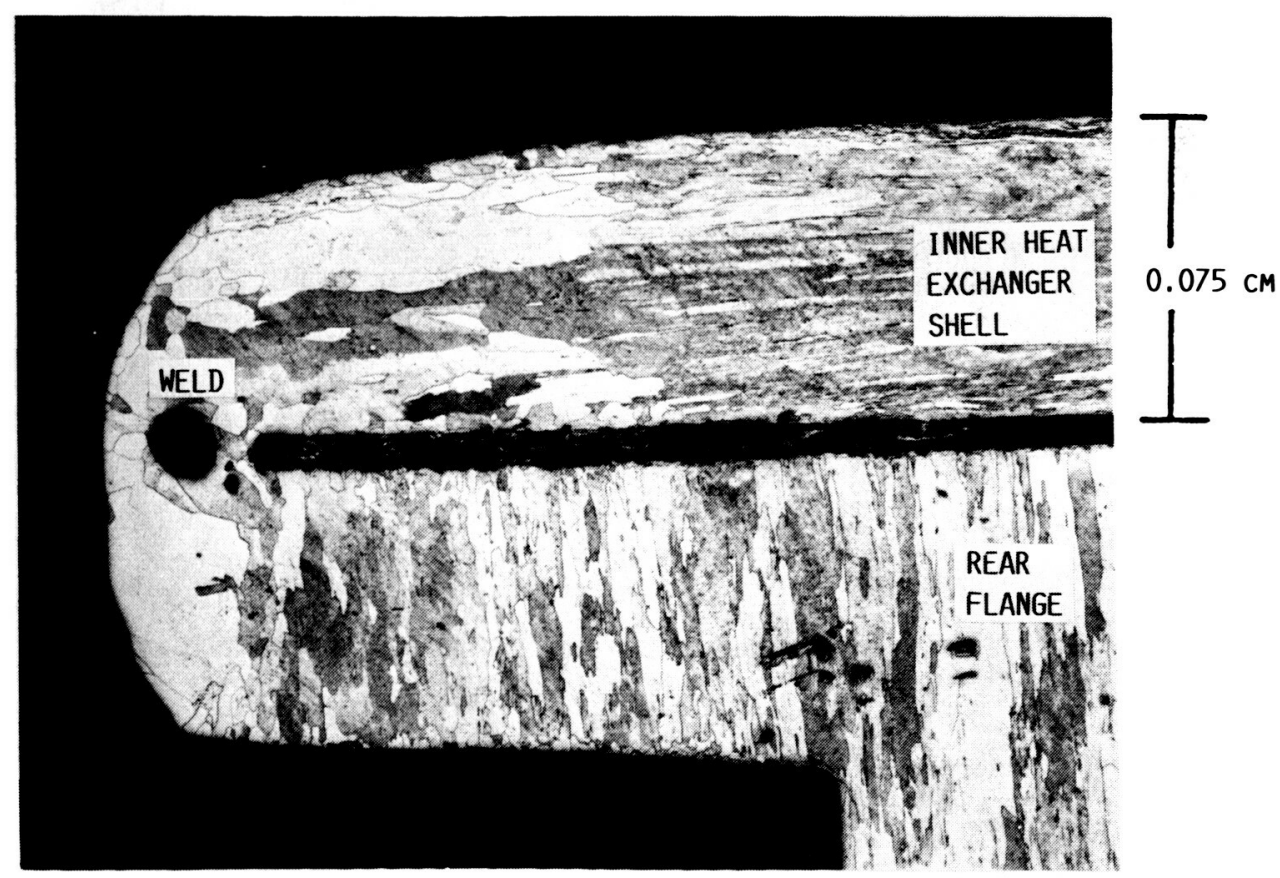

(B) FLANGE/INNER HEAT EXCHANGER TUBE (EB WELD NO. 3, FIG. 7).

FIgURE 9. - EB WELD OF GRAIN-STABILIZED PT RESISTOJET COMPONENTS. 


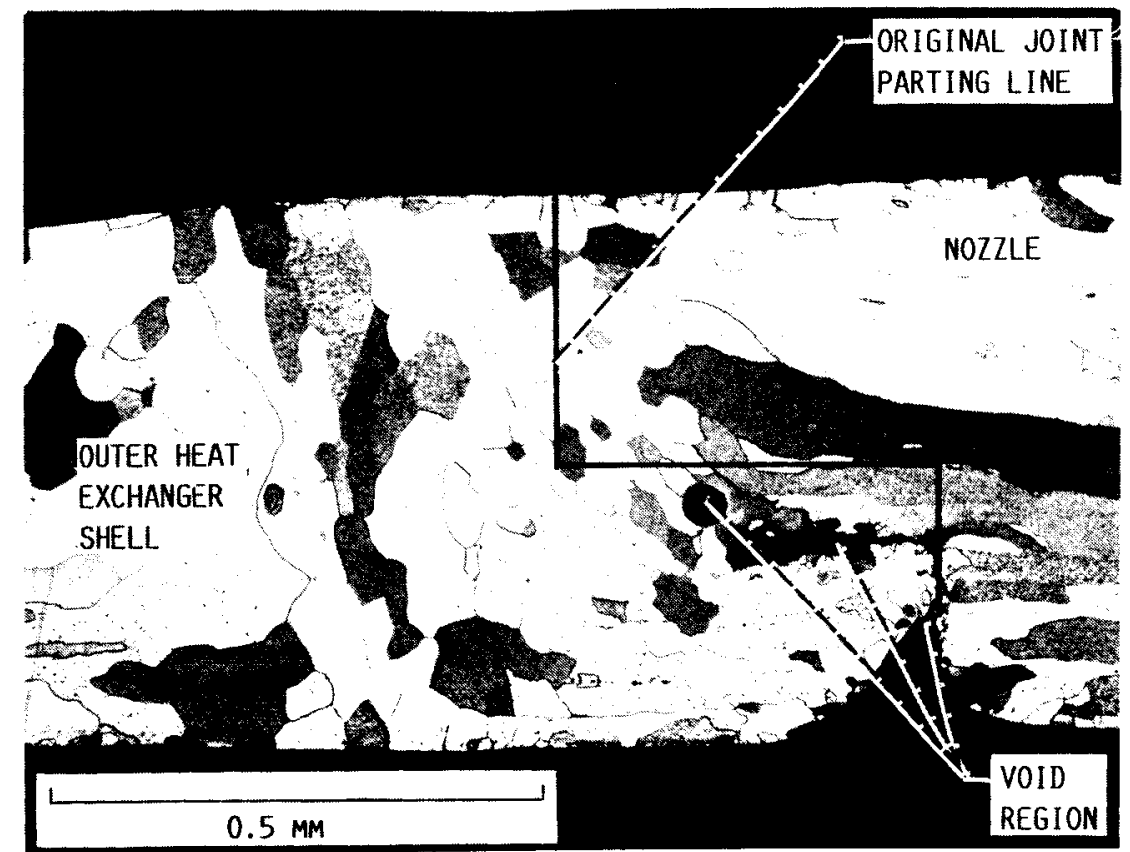

(C) OUTER SHELL/NOZZLE (EB WELD NO. 3, FIG. 7).

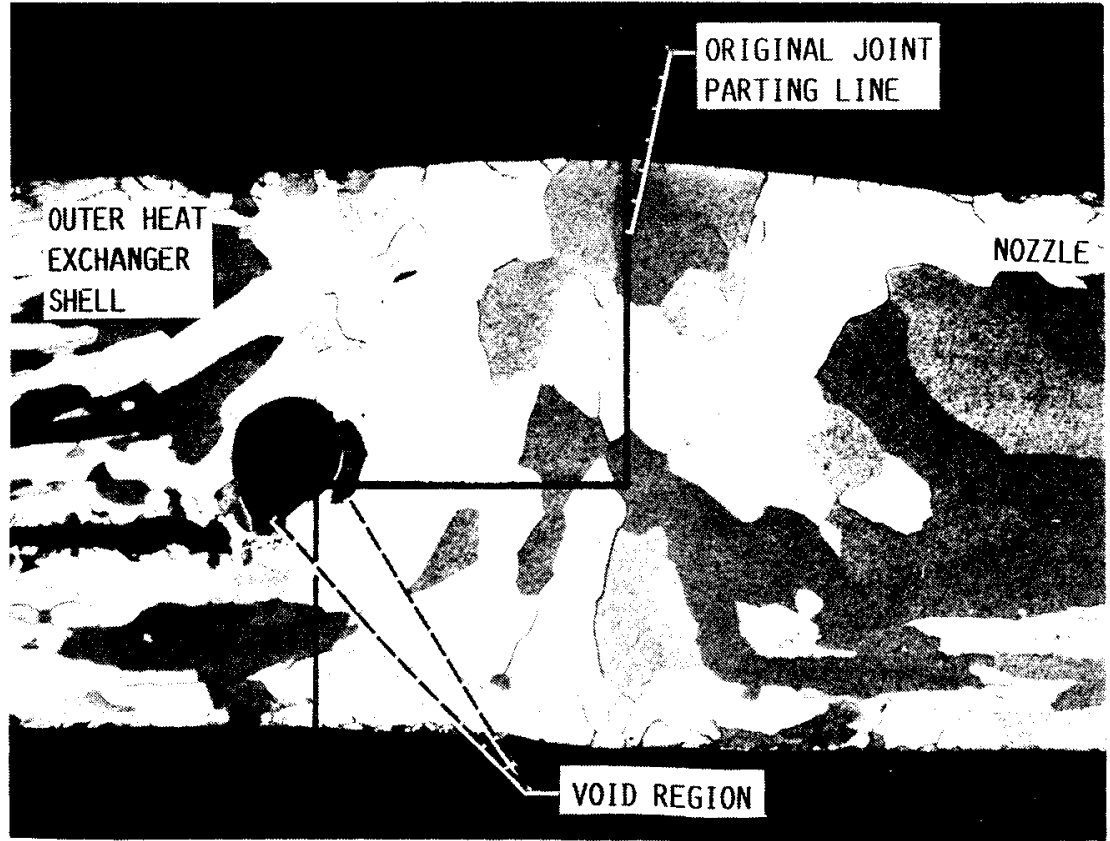

(D) OUTER SHELL/NOZZLE (EB WELD N0. 4, FIG. 7).

FIGURE 9. - CONCLUDED. 


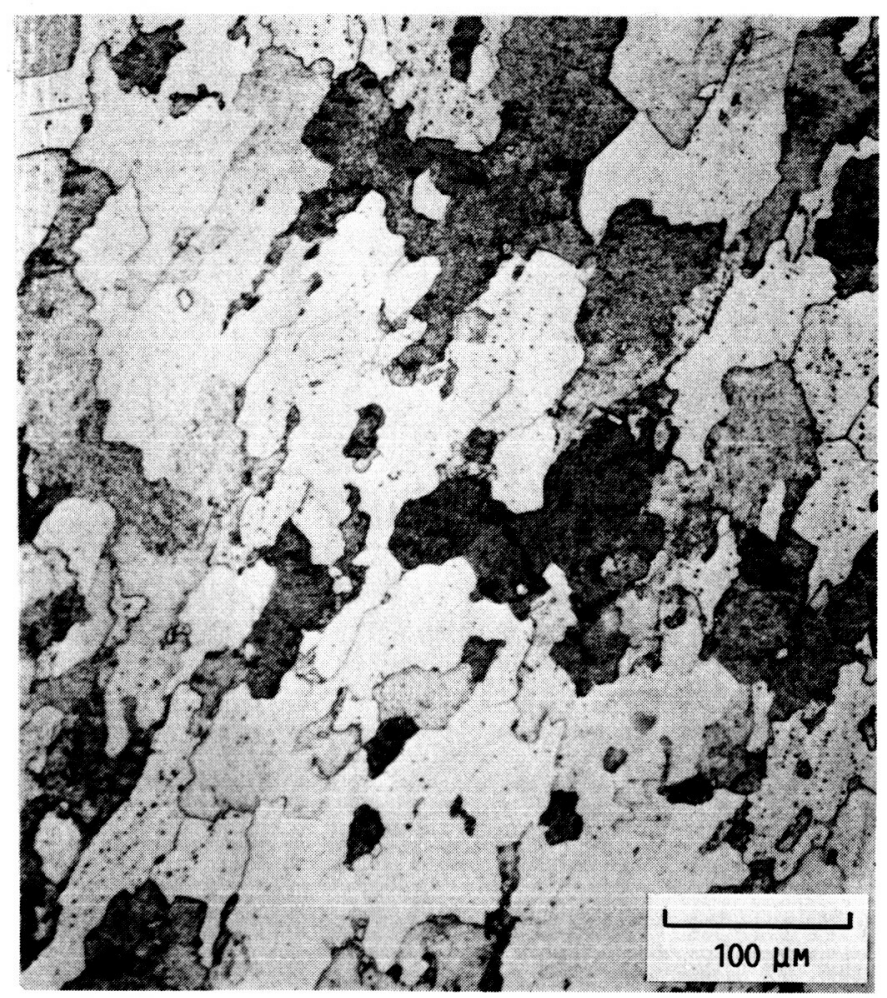

(A) INLET REGION (WELD NO. 7, FIG. 7).

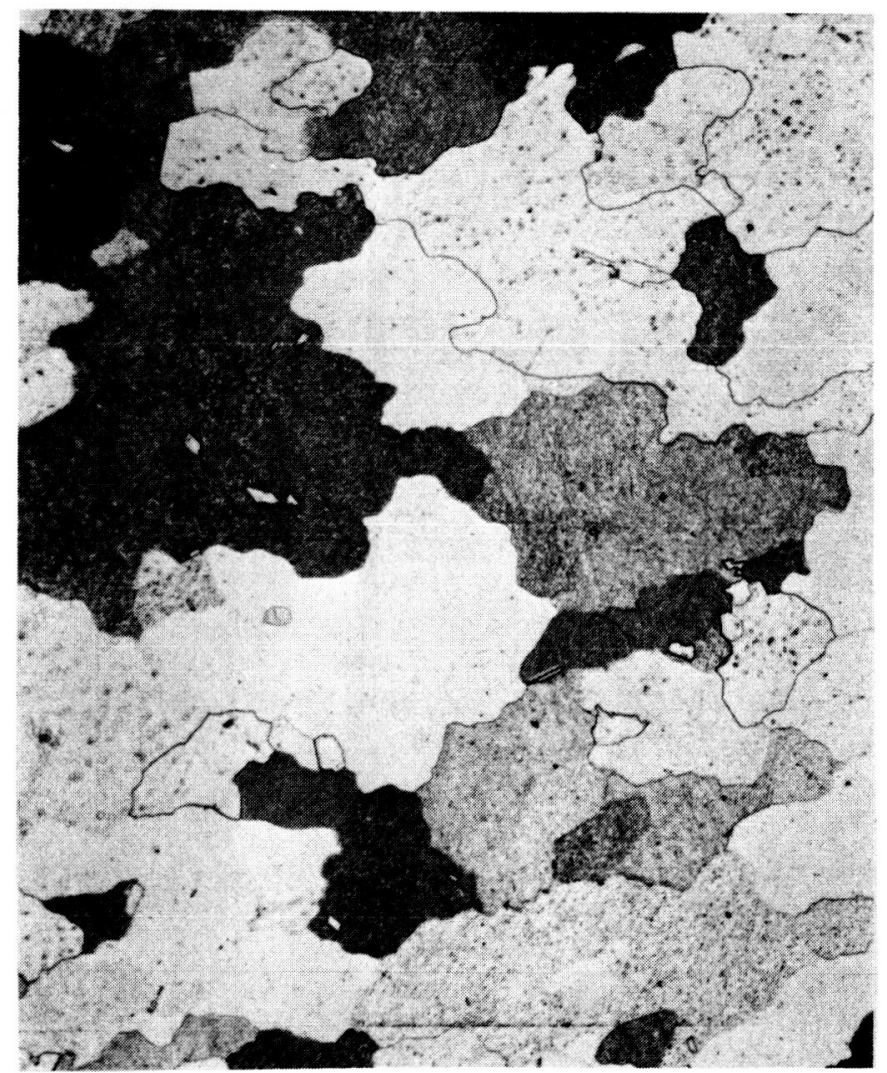

(B) NOZZLE REGION (WELD N0, 8, FIG. 7).

FIGURE 10. - GRAIN STRUCTURE OF INNER HEAT EXCHANGER SHELL. 

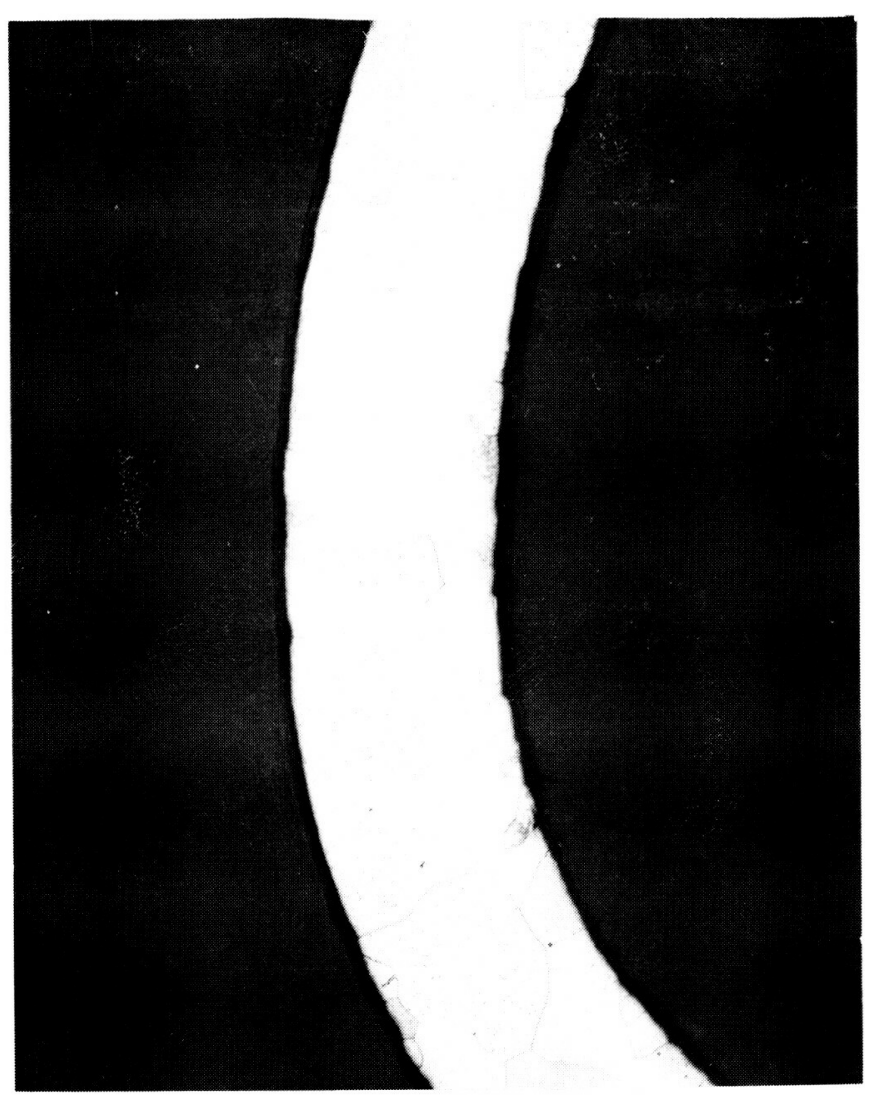

ORUMMAR PAEE 13 OF POOR QUALTY

(A) NORMAL TO TUBE AXIS.

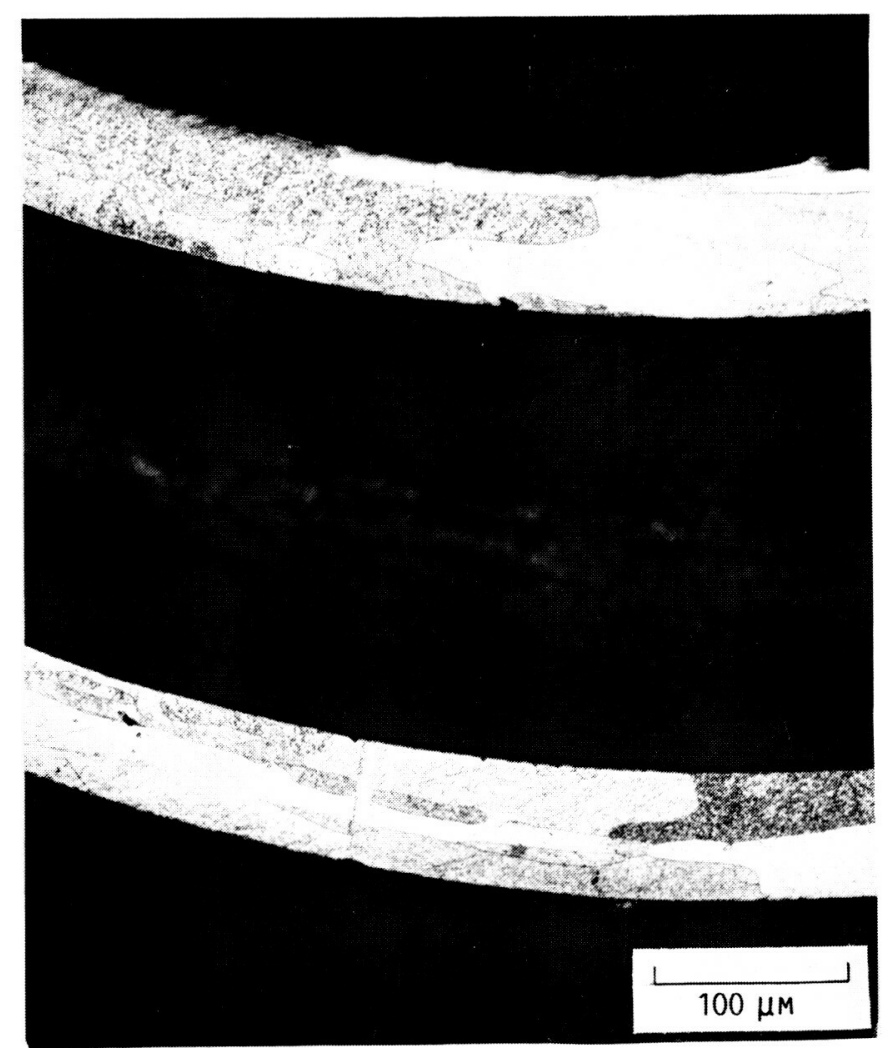

(B) PARALLEL TO TUBE AXIS.

FIGURE 11. - GRAIN STRUCTURE IN HEATER TUBE. 


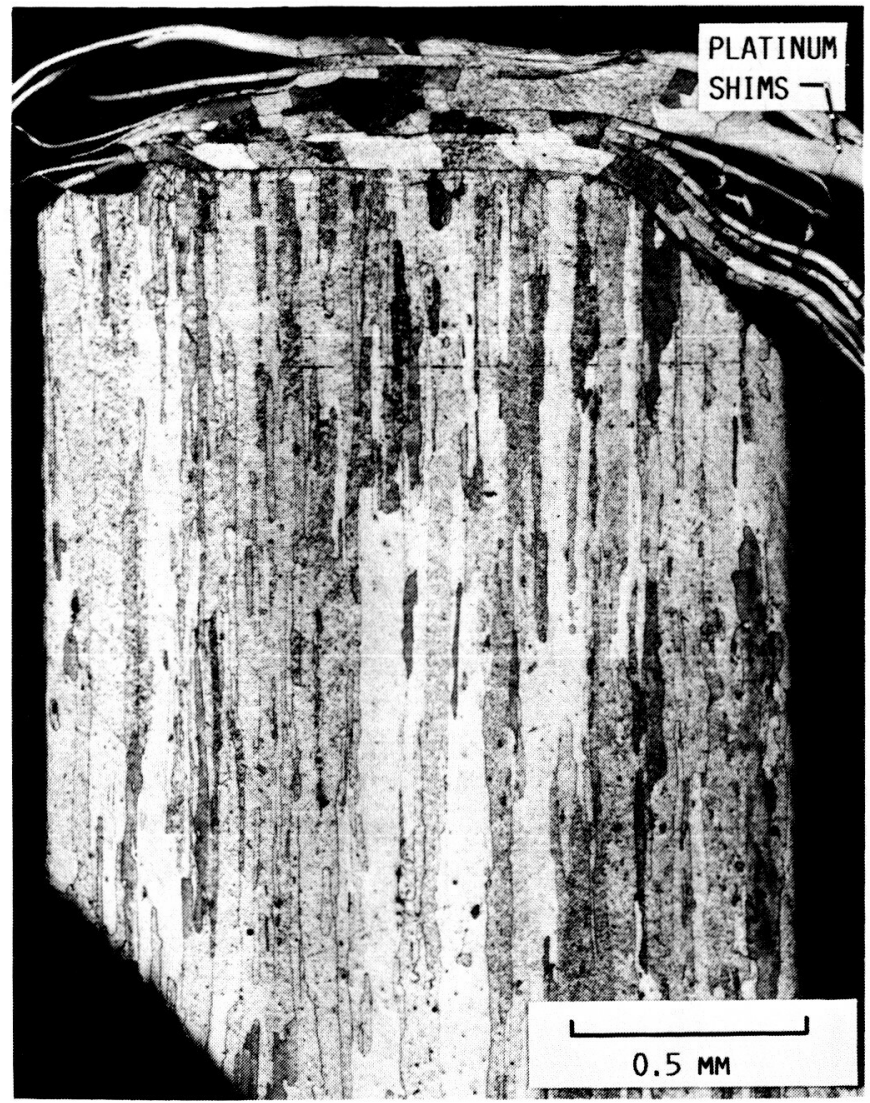

FIGURE 12. - GRAIN STRUCTURE IN HEAT TERMINATION DISK AT INTERFACE WITH INNER HEAT EXCHANGER WALL (PLATINUM FOIL SHIMS SHOWN, SECTION NO. 9, FIG. 7).
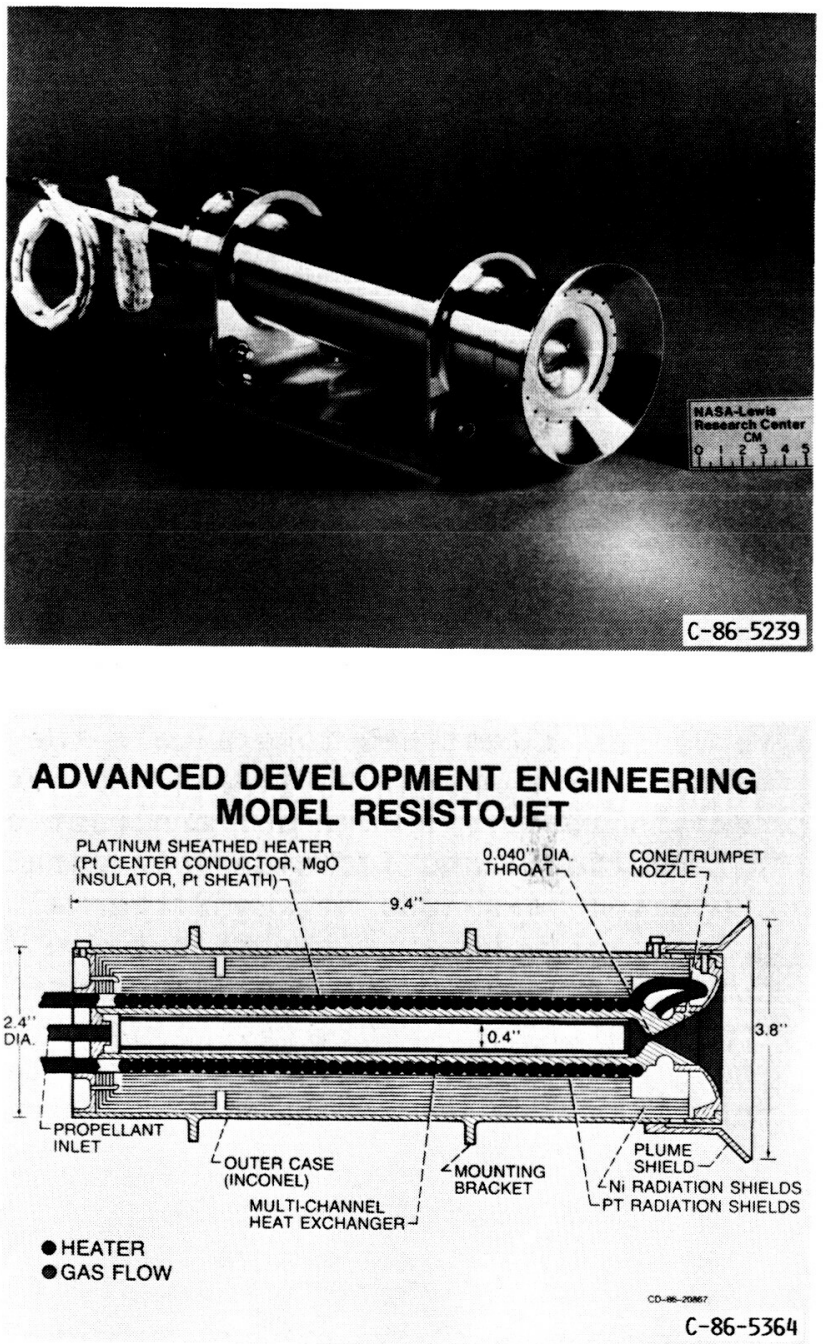

FIGURE 13. - ENGINEERING MODEL RESISTOJET. 


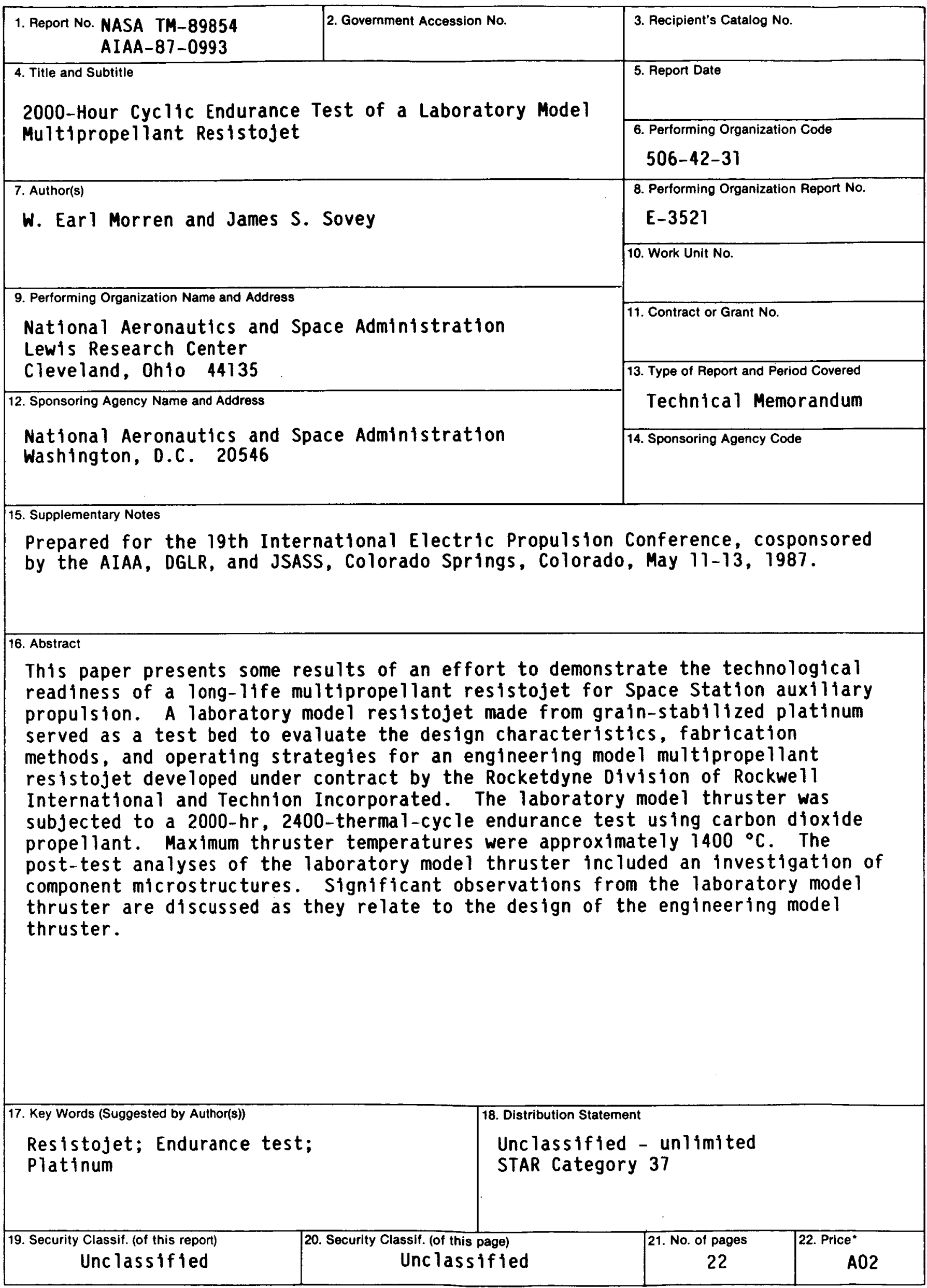

"For sale by the National Technical Information Service, Springfield, Virginia 22161 